\title{
WHO publications available in the Peradeniya Medical Library: a bibliometric study
}

Perera, P.A.S.H. ${ }^{1}$

\begin{abstract}
The collection of publications by World Health Organization (WHO) in the Medical Library contains documents published since 1950 to date which has been made available to the library free of charge by the WHO. The collection is very much under-used. A bibliometric study on the collection was carried out with the objective of making the readership and the library staff aware of what is available in the collection, which would indirectly improve the usage. The collection of WHO publications which is available in the Medical Library except periodicals was considered for the study. A head count on the total number of publications under study was obtained. The numbers of items in major subject divisions and in the most popular subject area within these divisions were counted separately. Contents of each publication in the collection were carefully read through in order to identify any specific topic or aspect of health on which the coverage was dominant. Items in monograph series were counted separately. Geographical coverage of contents of the publications was examined. A chronological evaluation of the collection was done by counting items published in each decade from 1950 to 2011 . Data thus gathered was analyzed to obtain percentages of publications available in each category with respect to the total number. The results revealed that the collection contained information on various health related topics at national, regional and global levels. Collection needs to be improved by acquiring current publications.
\end{abstract}

Keywords: Bibliometry, bibliometrics, publication counts, health information

\section{Introduction}

"Studies of publication patterns, also known as Bibliometrics is a type of research method used in Library and Information Sciences (LIS)." (Thanuskodi ,2010). "The main

\footnotetext{
1 Senior Assistant Librarian, Medical Library, University of Peradeniya, Sri Lanka. Email: sriper@pdn.ac.lk
} 
Journal of the University Librarians Association, Sri Lanka, Vol. 16, Issue 2, July 2012

derivatives of bibliometrics are: publication counts, citation counts, co-citation analysis, co-word analysis, scientific 'mapping' and citations in patents. This can lead to better organization of information resources, which is essential for effective and efficient use". (Thanuskodi ,2010)

The World Health Organization (WHO) is the most prestigious international organization known to exist that is committed to address and support in global health related issues. WHO is the directing and coordinating authority for health within the United Nations system.

Documents and publications published by WHO, in its regional offices and in the Head Quarters in Geneva are enormous in number. These are scattered in libraries all over the world. The contents of these publications are diverse in subject coverage. Information contain in these publications would be useful for various categories of readers such as, health administrators, health educators, media, health and biomedical researchers, planners, teaching faculties etc.. Peradeniya Medical Library receives a considerable number of complimentary copies of WHO publications on a regular basis. In the library these publications are catalogued and shelved in a separate area called 'WHO Collection' in the reference section. It was observed over the years that the usage of this collection is very low. Thus a bibliometric study to analyze the subject coverage of the collection available in the medical library would be a useful exercise as the outcome would be helpful in the promotion of its usage.

\section{Objectives of the Study}

1. To make the users of the library aware of the available literature

2. To use the outcome of the study to improve the usage of the collection

3. To study the subject coverage

4. To keep a record on the contents of the collection

5. To identify laps in order to improve the collection 
Journal of the University Librarians Association, Sri Lanka, Vol. 16, Issue 2, July 2012

\section{Methodology}

The collection of WHO publications which is available in the Medical Library at University of Peradeniya as at end of July 2011 were taken into consideration for the study. The collection includes books, monographs of series, reports etc. and periodicals. Periodicals were not included in the study. A head count on the total collection under study was obtained. The collection was separated into major subject divisions based on the number of items available in each subject division. The number of publications in each subject division and in the most popular subject area (Clinical Medicine - selected empirically as the subject in which circulation of books is highest in the library) within these divisions was counted separately. Publications which couldn't be categorized into any specific subject by content were counted as a separate group (miscellaneous). Contents of each publication in the collection were carefully read through in order to identify any specific topic or aspect of health on which the coverage is dominant. Items in monograph series were counted separately when numbers of those items were large enough to be separated out. Geographical coverage of the content of publications was examined only when it contained an issue pertaining to a certain geographical area. A chronological evaluation of the collection was done by counting items published in each decade from 1950 through 2011. Data were tabulated and percentages were obtained using 2007 version of Windows Excel package.

\section{Results and Discussion}

The total number (head count) of publications (books, monographs in series, reports etc.) in the WHO collection was 2791. Disciplines which were covered by the collection substantially with respect to the total number are shown in Table 1 and Figure 1.

It shows that the discipline which had the highest number of publications was Environmental Health (851), next highest was in Clinical Medicine (550) and the order follows as Pharmacology \& Toxicology (308), General Medicine (262), Health Care (230), Social Services (162) etc.. 
Journal of the University Librarians Association, Sri Lanka, Vol. 16, Issue 2, July 2012

Table 1: Subject and number of publications

\begin{tabular}{|c|c|c|}
\hline Subject & Number of publications & $\begin{array}{l}\text { Percentage } \\
\text { Ofthe Total }\end{array}$ \\
\hline Agriculture & 15 & 0.54 \\
\hline Bibliography & 31 & 1.11 \\
\hline Biological Sciences & 17 & 0.61 \\
\hline Clinical Medicine & 550 & 19.71 \\
\hline Economics & 24 & 0.86 \\
\hline Education & 14 & 0.5 \\
\hline Engineering & 8 & 0.29 \\
\hline Environmental Health & 851 & 30.49 \\
\hline Ethics & 1 & 0.04 \\
\hline Familyliving & 13 & 0.47 \\
\hline General Medicine & 262 & 9.39 \\
\hline Gynecology \& Obstetrics & 42 & 1.5 \\
\hline Healthcare & 230 & 8.24 \\
\hline Law & 5 & 0.18 \\
\hline Miscellaneous & 91 & 3.5 \\
\hline Pediatrics & 25 & 0.9 \\
\hline Pharmacology & 308 & 11.04 \\
\hline Physical Sciences & 19 & 0.68 \\
\hline Researchmethods & 1 & 0.04 \\
\hline Social senvices & 162 & 6.4 \\
\hline Social problems & 36 & 1.29 \\
\hline Social welfare & 3 & 0.11 \\
\hline Sociology & 2 & 0.07 \\
\hline Statistics & 31 & 1.11 \\
\hline Surgery & 50 & 1.9 \\
\hline Total & 2791 & \\
\hline
\end{tabular}




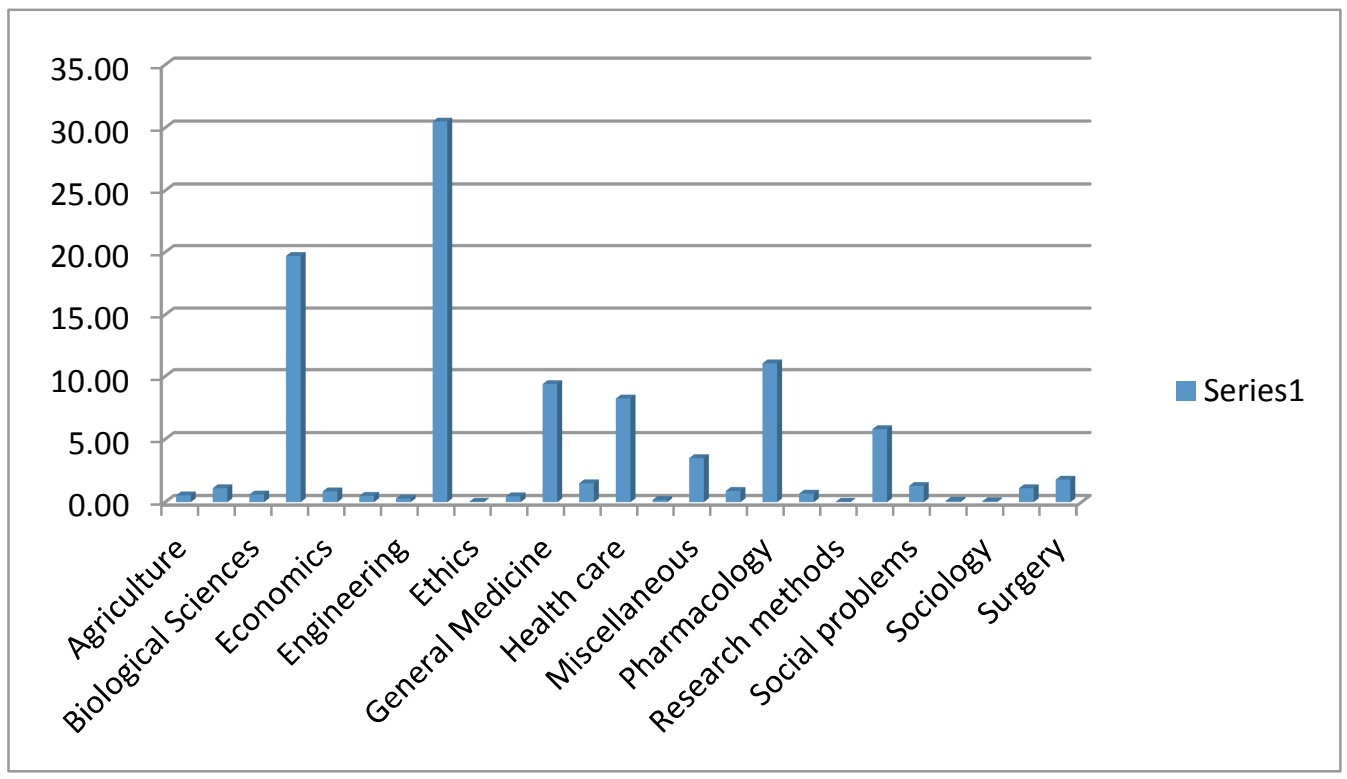

Figure 1: Percentage of number of publications vs subject

Further study for specific topics covered by the publications in Clinical Medicine (Table 2) showed that there are 40 publications on AIDS, 18 on Cancer, 4 publications on Dengue , 14 on Malaria, 19 on Mental health and 39 on Tuberculosis,. Topics which were prominent in coverage among the collection were: World Tobacco Control, Global Tuberculosis Control, Cancer research, Control of Tropical Diseases, Global AIDS Epidemic, Influenza Epidemic, Family Health, Health System Planning \& Services and Drug Information.

During the study It was revealed that the collection includes very valuable and important publications such as "The International Classification of Diseases (ICD)" which is used internationally to classify diseases and other vital records on health problems , "Guidelines for management of snake bite in South-east Asian region" and "Dengue: Guidelines for diagnosis, treatment, prevention and control". 
Table 2: Number of publications vs special areas in clinical medicine

\begin{tabular}{l|c}
\hline Special areas in Clinical Mediaine & Numberof Publications \\
\hline AIDS & 40 \\
Cancer & 18 \\
Dengue & 04 \\
Malaria & 14 \\
Mental health & 19 \\
Tuberculosis & 39 \\
\hline Total & 134 \\
\hline
\end{tabular}

Following monograph series contained substantial number of items within the series as shown in Table 3. It shows that $45 \%$ of the publications in the collection belong to the monograph series.

Table 3: Number of publications vs series

\begin{tabular}{l|cc}
\hline Publication & $\begin{array}{c}\text { Number of } \\
\text { publications }\end{array}$ & $\begin{array}{c}\text { Percentage of } \\
\text { the total }\end{array}$ \\
\hline IARC (International Agency for Researchon Cancer) & 88 & 3.2 \\
IPCS(International Programmeon Chemical Safety) & 280 & 10 \\
IPCS-TOM (International Programme on Chemical Safety- & 83 & 2.9 \\
WHOTechnical ReportSeries & 824 & 29.5 \\
\hline Total & 1275 & 45.68 \\
\hline
\end{tabular}

Distribution of publications according to year of publication is shown in Table 4. It shows that only around $20 \%$ of the WHO collection is published after 2000 and around $48 \%$ of it is published after 1990 . 
Journal of the University Librarians Association, Sri Lanka, Vol. 16, Issue 2, July 2012

Table 4: Number of publications vs year of publication

\begin{tabular}{l|cc}
\hline Yearof Publication & Number of Publications & Percentage of the Total \\
\hline $1950-1959$ & 167 & 5.98 \\
$1060-1969$ & 142 & 5.07 \\
$1970-1979$ & 377 & 13.50 \\
$1980-1989$ & 710 & 25.44 \\
$1990-1999$ & 817 & 29.27 \\
$2000-2009$ & 558 & 19.99 \\
$2010-2011$ & 20 & 0.72 \\
\hline Total & $\mathbf{2 7 9 1}$ \\
\hline
\end{tabular}

The content of certain number of publications dealt with issues pertaining to various geographical areas. Distribution of these publications according to geographical coverage of the content is shown in Table 5. It was found that content of 70 publications had discussed global issues, 25 publications on issues relevant to developing countries, 104 publications on South East Asian regional matters and there were five publications specifically on Sri Lankan issues. Rest of the publications is of international coverage. There were 5 case-reports on various issues in different countries.

Table 5: Number of publications vs geographical coverage of the content

\begin{tabular}{l|c}
\hline Geographical coverage of the content & Number of publications \\
\hline Developing countries & 25 \\
Global & 70 \\
South EastAsian region & 104 \\
Srilanka & 05 \\
\hline Total & $\mathbf{2 0 4}$ \\
\hline
\end{tabular}




\section{Conclusion}

The study provided an insight into this valuable though much under-used collection of health information. According to the findings of the study the publications in the WHO collection were scattered in 24 disciplines with 91 publications written on miscellaneous subjects. The collection contained valuable and important publications on some of the current health topics. The contents were of national, regional and global level. The contents of some publications were focused specifically on developing countries and on countries in the South-East-Asia. The four major monograph series contain $45 \%$ of the collection. The study provided a breakdown of publications according to year of publication. It shows that the collection provides recent information to a certain extent though it doesn't contain much of current information. Therefore, the collection should be improved by acquiring current publications which would eventually lead to better usage of the collection.

\section{References}

Thanuskodi, S. (2010). Journal of social sciences: a bibliometric study. Journal of Social Science, 24(2), 77-80.

Thanuskodi, S. (2010). Bibliometric analysis of The Journal Library Philosophy and Practice from 2005 - 2009, Journal Library Philosophy and Practice, (October). 